\title{
Experiência estética e cotidiano institucional: novos mapas para subjetivar espaços destinados à saúde mental
}

MECCA, R.C.; CASTRO, E.D. Aesthetic experience and institutional daily life: new maps for subjectively dealing with spaces for mental healthcare. Interface - Comunic., Saúde, Educ., v.12, n.25, p.377-86, abr./jun. 2008.

The use of artistic activities as agents for mental healthcare practices in relation to the organization of daily life and institutional spaces, in substitutive services such as at psychosocial care centers, is discussed. The importance of porosity in this daily life to welcome users' creations and link them with the other activities that structure daily life and occupy institutional spaces is discussed. It is advocated that institutional spaces need to reflect the intrinsic characteristics and needs of people who are treated there, and for the institution to function as a backdrop for semantic linkage of the subjects' experiences and their possible dialogue with culture.

Key words: Occupacional therapy. Institutionalization. Mental health. Culture. Activities of daily living.
Discute-se o uso das atividades artísticas como agenciadoras de práticas de cuidado em saúde mental, vinculadas à organização do cotidiano e do espaço institucional em serviços substitutivos como os Centros de Atenção Psicossocial (CAPS). Discorre-se sobre a importância da porosidade desse cotidiano para o acolhimento da criação dos usuários e a articulação desta com as demais atividades que estruturam o cotidiano e habitam os espaços institucionais. Defende-se a necessidade de o espaço institucional refletir o estilo de ser e as necessidades das pessoas que lá se tratam, e de a instituição funcionar como pano de fundo para a articulação semântica das experiências dos sujeitos e seus possíveis diálogos com a cultura.

Palavras-chave: Terapia ocupacional. Institucionalização. Saúde mental. Cultura. Atividades cotidianas.

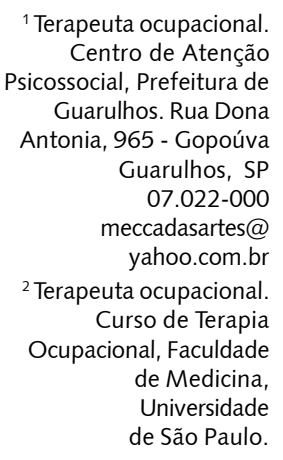




\section{Introdução}

Este artigo discorre sobre o uso de atividades artísticas em um Centro de Atenção Psicossocial (CAPS) destinado à assistência de pessoas com transtornos psíquicos graves, suas possíveis correlações com a construção do cotidiano institucional e com a apropriação e personificação deste cotidiano pelos usuários do serviço. Partimos da experiência do grupo Oficina de Bricolagem do CAPS da Prefeitura Municipal de Guarulhos e propusemos fazer uma compreensão das experiências desenvolvidas no grupo como facilitadoras do acolhimento de modos de existência diversos e da ancoragem destes numa rede de significação coletiva. Experiências estas agenciadoras de um reconhecimento de si na cultura e promotoras do sentimento de filiação. O presente trabalho compõe parte de nossa dissertação de mestrado na qual o grupo em questão é campo de pesquisa.

A Oficina de Bricolagem é um grupo aberto aos usuários que estão em tratamento intensivo e semiintensivo no CAPS, realizado semanalmente, e tem como proposta produzir trabalhos artísticos grupais como: painéis, esculturas, instalações, entre outros, que são expostos no ambiente do próprio CAPS, e por vezes em outros espaços da cidade. Sua finalidade consiste em possibilitar aos usuários deixarem suas marcas na composição do ambiente da instituição, e que, com base nisso, se trabalhe o vínculo dos usuários com o serviço para que este possa tornar-se referência de cuidado para os mesmos. Fragmentos da história dos sujeitos passam a compor fisicamente a história da instituição e esta passa a refletir o estilo de ser das pessoas que lá se tratam.

Nossa investigação acompanhou a participação de 23 usuários do CAPS na Oficina durante 13 meses, porém algumas passagens aqui relatadas ocorreram antes do período da coleta, objetivando um resgate histórico do grupo. O método utilizado foi a pesquisa-ação, que consta da análise e reflexão de um projeto de intervenção, proposto no campo de pesquisa pelo próprio pesquisador, em construção conjunta e interativa com o grupo, que intervém no processo de coleta, definição de problemas e análise de dados. Pressupõe um processo de emancipação e apropriação da pesquisa pelos sujeitos, pois coloca em foco a geração de soluções para problemas práticos e o desenvolvimento de habilidades e capacidades, fazendo com que se engajem na pesquisa e no desenvolvimento e implementação de atividades (Meyer, 2005).

Nesse sentido, pensamos na escolha de um método em estreita associação com a prática em terapia ocupacional desenvolvida na oficina, cujo objetivo é ofertar cuidado e atenção a pessoas que, por conta de um sofrimento psíquico agudo, têm seu potencial de ação fragilizado, pois se encontram em situação de ruptura de laços sociais, paralisação do curso da vida, desestruturação do cotidiano e dificuldade de se envolver em atividades, delas se apropriarem e por elas serem socialmente reconhecidos.

Ofertamos um campo de experimentação com relação ao fazer, contextualizado na relação terapêutica e na construção da narrativa pessoal, que se inicia por uma escuta e observação: das potencialidades e dificuldades de cada um; dos desejos, expectativas, fragmentos da história pessoal; do estilo de ser do sujeito impresso no fazer, e da poética pessoal. Deste processo, surgem propostas de atividades artísticas organizadas num projeto grupal, discutidas com os participantes e conectadas com suas necessidades, na tentativa de alinhavar os sujeitos numa proposição estética comum, que abra espaço para o acontecer poético e potencialize desdobramentos deste fazer nas diversas esferas da vida e do cotidiano, tornando-os atores no processo de realização das atividades.

A oficina teve início em setembro de 2001, quando o CAPS de Guarulhos mudou suas instalações para o local onde antes era o antigo Instituto de Psiquiatria de Guarulhos, desativado há alguns anos, local de internação e experiências traumatizantes para muitos de nossos usuários e seus familiares. Por um tempo após a mudança, convivemos com a reforma daquele espaço, a troca de pisos, a quebra de paredes, as conversas com os arquitetos para soluções que melhor atendessem aos projetos da equipe. Com isso, percebemos a necessidade de também envolver os usuários nesse processo de transformação de um espaço físico que refletia nas formas de pensar as modalidades e práticas de atenção em saúde mental para esta população.

A proposta era de acompanhar processos de criação que trouxessem uma transformação física daquele espaço com base em conteúdos, idéias, projetos e desejos dos usuários. Fazer do CAPS uma 
morada para projetos de desenvolvimento pessoal e propor aos usuários que, em sua passagem pela instituição, pudessem contribuir para o acontecer histórico, tanto no nível microfísico, quanto no nível macropolítico, pensando nas transformações necessárias à atenção em saúde mental no município.

Segundo Saraceno (1999), o trabalho de transformação na lógica da atenção em substituição ao modelo manicomial tem muito a ver com a desinstitucionalização das práticas, com a humanização e os direitos, com a subjetivação dos indivíduos, mas, sempre e em cada momento, tem a ver com espaços concretos nos quais as pessoas comem, dormem, caminham, falam. Cita Goffman (1968) apud Saraceno (1999) ao dizer que a desmontagem institucional é, sobretudo, um trabalho de desmontagem das funções espaciais, de reaquisição do direito ao uso dos espaços, de subjetivação e de ressimbolização dos espaços para que legitimem a "grandiosa banalidade cotidiana".

A participação dos usuários na reforma tanto física quanto ideológica da instituição nos remeteu a nomear, o grupo, de Oficina de Bricolagem. A princípio, levamos em consideração o termo bricolagem no sentido de seu uso comum: utilizar materiais de construção de diversos tipos para intervir de modo próprio na reforma de ambientes de maneira criativa. Com o tempo e com base em processos criativos desenvolvidos no grupo, percebemos que bricolagem também remetia a outros sentidos ligados à arte de combinar materiais de origens distintas, histórias e significados diversos em uma produção conjunta, produção estética da convivência de diferentes.

Pensamos que o trabalho de intervenção concreta nos espaços vividos favorece uma cultura da diferença e promove mudanças tanto na forma como os sujeitos atendidos se relacionam com o fazer, e por ele são reconhecidos, como nos modos operandis dos profissionais do serviço. Mas para que isto ocorra, é necessário caminhar no sentido de potencializar o encontro entre as singularidades, abarcar o contato com a estranheza e tornar coletivas as experiências.

Sennett (1997) alerta para a relação das pessoas com o espaço urbano das metrópoles contemporâneas como local de passagem marcado pela velocidade e passividade dos corpos, pelo individualismo e pela fragmentação. Os deslocamentos são cada vez mais rápidos num ambiente cujas referências tornam-se secundárias. Os corpos se movem sem obstrução e com passividade por cenários a se passar à vista e para destinos fragmentados e descontínuos. O individualismo moderno sedimentou o silêncio e a passividade dos cidadãos perante a diferença numa ordem que significa falta de contato. Assim, a vida cotidiana vai sendo consumida por esforços que tendem a minimizar e evitar conflitos com aquilo que é estranho. O autor aponta que, até nas metrópoles multiculturais, as pessoas não acolhem a diferença e, na maioria das vezes, a melhor expectativa está na tolerância, já que a velocidade e a fragmentação do meio fortalecem o rápido julgamento do comportamento daqueles que não pertencem ao lugar. $\mathrm{O}$ autor diz que jamais seremos capazes de captar a diferença alheia se não reconhecermos nossa fragilidade e estranheza e mudarmos a compreensão de nossos corpos como auto-suficientes. Para ele, a compaixão cívica deve ser movida por esta carência, e não pela boa vontade ou retidão política.

Por um bom tempo na oficina, os interesses em se trabalhar com os espaços estiveram direcionados para o desenvolvimento de trabalhos grupais em arte, que utilizavam materiais que sobravam da reforma. No início, o encontro com materiais remanescentes do antigo hospital psiquiátrico resgatou memórias e a necessidade, tanto da equipe como dos usuários, de transformá-los criativamente para que pudessem marcar um rito de passagem, uma nova forma de utilizar o espaço e de nele desenvolver outras práticas. A porta da cela forte encontrada entre os entulhos foi chumbada num suporte de cimento e ganhou um olho entalhado na madeira que, de fora, a tudo vigiava. O antigo piso do hospital psiquiátrico foi transformado em um mosaico que captava corpos celestes e explosões no espaço sideral. Objetos e materiais de uso hospitalar eram ressignificados e suas formas remetiam a outras viagens: uma velha caldeira de esterilização se tornou uma nave que carregava fotografias familiares e aspirações futuras. Lençóis do hospital, gentilmente cedidos pela enfermagem, viraram painéis de pintura com cenas da história de cada um dos usuários. Sobras de retalhos da oficina de costura se transformaram num estandarte de patchwork, que resgatava histórias ligadas a experiências no campo do fazer.

As experiências de criação artística na oficina uniam fragmentos da história da atenção em saúde mental e da história pessoal dos sujeitos, e os ressignificavam para, então, agenciar transformações de estados de ser, enrijecidos na dependência de outros, no lugar da doença, no não poder desejar, demandar ou opinar sobre o coletivo, para um novo acontecer histórico compartilhado. 
As marcas deste processo se deram mediante as produções, que iniciaram com a transformação da cela forte destituída de poder por meio de uma alegoria da vigilância, até a pintura e costura de experiências que apontavam para desejos, necessidades e projetos de vida dos usuários. Fazia-se necessário exumar os destroços da atenção pautada na tutela e no controle dos corpos e dos discursos, para deles, de certa forma, nos libertarmos e podermos então desejar, encontrar o outro e resgatar seus projetos.

Pensamos que essa passagem criativa do grupo também reflete as transformações históricas no contexto da saúde mental. Talvez, nos serviços substitutivos, não tenhamos de lidar mais com a violência explícita do modelo manicomial, mas, ainda assim, com redes de vigilância que se calcam nas entranhas do cotidiano institucional e no uso de seu espaço. Deleuze (1992), ao refletir sobre as novas formas de controle social, nos diz que estas são exercidas pelo estabelecimento de formas de controle contínuo e ilimitado, com a "implantação progressiva e dispersa de um novo regime de dominação" (Deleuze, 1992, p.225).

Certeau (1998) desenvolve uma pesquisa sobre a criatividade cotidiana e as maneiras pelas quais os sujeitos subvertem as representações, leis e produtos impostos pela ordem econômica dominante. Em sua tese, usa a palavra bricolagem para descrever a maneira pela qual os usuários consumidores de uma economia cultural dominante operam metamorfoses nas normas que lhe são impostas, e fazem uso delas segundo seus interesses próprios e suas próprias regras. Para tanto, reporta-se a Foucault para pensar uma substituição da análise das instituições localizáveis como aparelhos que exercem o poder, pelos "dispositivos que vampirizam as instituições e reorganizam clandestinamente o funcionamento do poder: procedimentos técnicos minúsculos, atuando sobre os detalhes, redistribuíram o espaço para transformá-lo no operador de uma vigilância generalizada" (Certeau, 1998, p.41).

Isto nos faz pensar sobre as transformações na lógica de exercício do poder dentro das instituições pós-reforma psiquiátrica, que substituem o modelo centralizado na internação hospitalar. É necessário um exercício cotidiano de auto-avaliação das equipes e de crítica às práticas que, em suas filigranas, tramitam a vigilância e a tutela, e que, na relação face a face com os usuários, operam o controle dos comportamentos e a instituição de modos de ser e de fazer meramente adaptados ao social. Este tipo de prática tende ao constante esvaziamento do fazer humano, que se torna mera execução de tarefas e perde gradualmente reconhecimento social. A nosso ver, este é um risco permanente nos serviços substitutivos.

Guatarri (2005) aponta que, na época contemporânea, a exacerbação de produção de bens materiais e imateriais em detrimento da consistência de territórios existenciais individuais e de grupo engendrou um vazio na subjetividade, que tende a se tornar cada vez mais sem recursos. Para o autor, vivemos atualmente degradações nos três domínios ecológicos nos quais se instaura a subjetividade: mental, social e ambiental. Ele propõe a construção de uma nova referência ecosófica, que indica linhas de recomposição das práxis humanas nos mais variados domínios, naquilo que concerne à vida cotidiana. Trata-se de se debruçar sobre os dispositivos de produção de subjetividade, indo no sentido da resingularização individual e/ou coletiva. Numa perspectiva de reinvenção constante, em contraposição aos processos que se congelam em repetições, o autor toma o paradigma estético para reconfigurar as práticas no campo da saúde, no qual cada desempenho concreto inaugura aberturas prospectivas à construção de territórios existenciais, com base na práxis que permita torná-los habitáveis por um projeto humano.

Atualmente, a cultura dominante tem o cotidiano como frente de estratégia de atuação. Signos que antes eram transmitidos por autoridades normativas, como a Igreja e o Estado, hoje são veiculados pelos meios de comunicação de massa, que difundem, com intensidade e onipresença maior do que aquelas instâncias, padrões normativos e valores homogeneizadores que acabam sendo incorporados à vida dos consumidores (Dias, 1998).

Porém, com base nisso, Certeau (1998) se pergunta: se for verdade que por toda parte na sociedade se estende uma rede de vigilância, como que uma sociedade inteira não se reduz a ela? Quais procedimentos populares permitem os sujeitos dela escaparem, jogarem e alterarem seus mecanismos de disciplina? O autor desenvolve a tese de que é por meio das "maneiras de fazer" dos sujeitos que consomem produtos e normas da cultura dominante, que estes se reapropriam do espaço organizado 
pelas técnicas da produção socioindustrial, numa atitude criativa que ele dá o nome de "bricoladora", pois combina inúmeras e infinitas metamorfoses das normas e maneiras singularizadas de se relacionar com elas (Certeau, 1998).

Sua tese coloca questões análogas e contrárias às abordadas por Foucault:

\begin{abstract}
Análogas, porque se trata de distinguir as operações quase microbianas que proliferam no seio das estruturas tecnocráticas e alteram seu funcionamento por uma multiplicidade de "táticas" articuladas sobre os "detalhes" do cotidiano; contrárias, por não se tratar mais de precisar como a violência da ordem se transforma em tecnologia disciplinar, mas de exumar as forças táticas e sub-reptícias que são assumidas pela criatividade bricoladora dos grupos e dos indivíduos presos agora nas redes de "vigilância". (Certeau, 1998, p.41)
\end{abstract}

Também podemos pensar nas diversas maneiras pelas quais os usuários do CAPS subvertem e se apropriam de sua lógica de funcionamento por meio das propostas com as atividades artísticas, colocando de si na constituição dos espaços que compõem a instituição e na estruturação de seu cotidiano. Em termos de uma análise institucional, uma reconstrução, cuja eficácia é da ordem estéticoexistencial, passa menos por leis ou programas burocráticos, e mais pela promoção de práticas inovadoras, pela disseminação de experiências alternativas, centradas no respeito à singularidade e no trabalho permanente de produção da subjetividade, que vai ganhando autonomia ao mesmo tempo em que vai se articulando ao social (Guatarri, 2005).

\title{
Cotidiano institucional
}

O conceito de cotidiano, no senso comum, parece se confundir com a idéia de rotina, de fatos encadeados em continuidade, de campo da necessidade e da repetição, de área reservada ao consumo e à cultura dominante. Porém, para muitos pensadores contemporâneos, este conceito difere de rotina, pois sugere mudança, dissolução de culturas, possibilidades de novos modos de ser. O que aponta para um significado ligado ao desejo, ao espaço mesmo de uma possível revolução cultural, pois está sempre em processo de ser reinventado pelas práticas de resistência à hegemonia e estratégias de sobrevivência à margem da dominação, que implicam sociabilidades e articulações intersubjetivas, mais do que discursos entre indivíduos conscientes (Dias, 1998).

Tomamos por referência o que Heller (1972) nos coloca por vida cotidiana, compreendida como o centro do acontecer histórico e da vida do homem, porque dela participa com todos os aspectos de sua individualidade e personalidade. Ela é construída nas relações sociais e se apresenta como um mundo intersubjetivo, um universo cuja participação acontece com outros homens e que tem as atividades humanas como seus elementos estruturais. As atividades compõem uma rede estrutural do cotidiano $e$ para que ele se processe é necessário uma certa dose de pragmatismo, generalização e imitação na forma como os comportamentos e condutas necessários à realização das atividades cotidianas são assimilados ou acionados. Realizamos as atividades no cotidiano de maneira automática, com pouca reflexão sobre as ações que se processam, e estabelecendo generalizações ou analogias de uma situação com outras para que possamos reagir ou decidir no cotidiano de maneira a manter o seu fluxo contínuo.

Porém, se características como pragmatismo, imitação, generalização se absolutizam no cotidiano, este se torna rotineiro e deixa de dar margem ao movimento, à forma singularizada de apreensão e desenvolvimento das atividades, e ocorre a alienação da vida cotidiana. Quando pensamos em um cotidiano que aponte para a saúde, ele deve se construir com base nas escolhas de cada sujeito e compartilhado numa rede de encontros capaz de absorver o que o sujeito puder expressar, a emergência do desejo e do sentido. Um cotidiano que se apresenta de maneira porosa ao aparecimento do inusitado, do estranho, às diversas formas de ser e de estar no mundo, às possibilidades de criação e de encontro do que é próprio com o que é compartilhado.

Falamos de saúde no sentido dado por Winnicott (1996), como a capacidade de o sujeito alcançar certa identificação com a sociedade sem perder muito de seus impulsos pessoais. Saúde em estreita ligação com a possibilidade de participação social e com a criatividade do sujeito num campo relacional. 
Sentir que vive a própria vida, reconhecer-se nela e ser reconhecido. Estar no coletivo sem perder o que lhe é próprio.

No CAPS, o cotidiano pode se constituir por esta rede de encontros e trajetórias entrecruzadas que configuram uma ambiência. A ambiência é o caldo, o entorno que dá sustentação e consistência às experiências vividas pelos sujeitos e suas significações, e pode ser transformada com base em suas necessidades. É a ambiência que diferencia o cotidiano do CAPS, no qual a participação pode ser experimentada. A participação ganha um lugar reconhecido no ambiente e é ela própria que irá constituir este ambiente, diferenciando-o de uma rotina alienante de atividades isoladas e gradeadas. As escolhas das atividades e os significados dados a elas dão o tom desta diferença.

Nas instituições, este cotidiano tende a ser atravessado por procedimentos comprometidos com os saberes técnicos e desconectados da emergência do inusitado, do desejo, da criatividade ou das potencialidades pessoais.

Segundo Maximino (2006), as instituições são conjuntos de relações e é impossível escapar delas, pois elas organizam esforços coletivos e alcançam resultados que não conseguiríamos sozinhos. Geralmente, elas nascem flexíveis e atentas às necessidades de seus membros, porém, com o tempo, vão se burocratizando e se afastando de seus objetivos iniciais, muitas vezes gastando toda sua energia apenas na própria sobrevivência. Sob o jugo do discurso médico, jurídico ou pedagógico, calam-se as necessidades e recursos dos sujeitos e estes se tornam casos. Empobrece-se a vida e a possibilidade criativa tão própria do humano.

Nesta situação, se faz necessário um contínuo esforço das equipes no aparecimento e no resgate de cada um como pessoa e do humano na constituição desses ambientes. Onde cada ser único, com sua história, seu jeito de ser e de fazer possa emergir e evoluir, não no sentido darwiniano do menos para o mais evoluído, mas como tal faz a escola de samba na avenida. Evoluir no sentido de construir um trajeto próprio, personificado e reconhecido em sua passagem, deixando sua marca estética na ambiência, ganhando territórios para sua existência.

Pensamos que as ações em saúde mental que se voltam para a construção de ambientes facilitadores da construção da subjetividade e da cidadania devam se debruçar sobre o cotidiano institucional, em suas micro-estruturas relacionais, tal qual uma rede de múltiplas negociações (Saraceno, 1999). Esta, na medida em que é articulada e flexível, aumenta a participação e a contratualidade social dos sujeitos. Por meio desta rede, é possível construir os espaços necessários para a medida humana, o acontecer de si mesmo e para o compartilhar desse acontecimento.

Segundo Saraceno (1999), um dos eixos sobre os quais se constrói a capacidade contratual dos pacientes em saúde mental é o habitar. A qualidade de vida e o poder contratual são representados por quanto o estar em qualquer lugar se torna um habitar este lugar. $O$ habitar remete a uma apropriação do espaço pelo indivíduo que demanda um grau de contratualidade elevado em relação à organização material e simbólica dos espaços e dos objetos, e a sua divisão afetiva com os outros. O habitar se diferencia de estar, que remete a um anonimato do indivíduo em relação ao espaço que em nada reflete suas necessidades ou poder de decisão.

\section{Apropriação do cotidiano e subjetivação dos espaços}

A Oficina de Bricolagem, ao propor aos usuários intervir criativamente nessa ambiência por meio do fazer artístico, possibilitava que uma experiência estética permeasse a relação dos indivíduos com a instituição, seu cotidiano e com as formas de cuidado que ela propunha. E os permitia ressignificar e reconstruir a rede de atividades e relações que articulava o cotidiano de cada um e de todos ao mesmo tempo, habitando este território de maneira própria e significativa.

Histórias, desejos, idéias, imagens, formas sem sentido previamente associado surgiam e eram articulados numa composição conjunta. A estrutura, materialidade e o tempo necessário para a realização das atividades artísticas marcavam uma narrativa do acontecer histórico dos encontros de cada um consigo mesmo e com os outros.

Esta cotidianidade do fazer em grupo favorecia a apropriação deste fazer pelos usuários e, muitas vezes, esta mesma experiência proporcionava a articulação de outros fazeres entre si no cotidiano de 
várias atividades. As atividades deixavam de ser entretenimento ou meras tarefas e passavam a resgatar o que nelas há de eminentemente humano: o sentido que fazem para quem as realiza.

As atividades artísticas, quando realizadas num ambiente facilitador, permitem a articulação deste fazer com os demais fazeres que compõem o cotidiano dos sujeitos, proporcionam a construção de novas redes de vinculação social, e rompem com representações culturais rígidas que discriminam e estigmatizam determinados fazeres e modos de ser, por divergirem de um padrão imposto. Isto gera interesse por novas possibilidades de atividades, vontade de instrumentalização técnica e expressão poética, ou seja, outros caminhos que não só a assistência pautada na doença (Castro, 2000).

Do pintar surgiu o desejo de ir a uma exposição de arte no grupo de passeio, e a partir dela se pensaram novas formas gestuais de realizar as pinceladas, de compor cores ou de dar expressão a figuras humanas. Do mosaico foi-se à marcenaria para montar uma estrutura que o sustentasse; da composição com palavras foi-se à biblioteca buscar livros de poesia concreta. Encontros e atividades foram sendo engendrados e passaram a dar sustentação à vivência dos sujeitos e ancorar as produções ao mundo de coisas produzidas pelos seres humanos. Ao transformar o cotidiano da instituição, esse processo modificava não só os usuários como também os membros da equipe, que participavam dos grupos com uma produção própria e reconheciam, na produção dos usuários, aspectos de sua história individual e sua potencialidade criativa.

Não é raro, nos grupos de terapia ocupacional, haver participação de pessoas da equipe instigadas pelo processo de realização das atividades. Normalmente, os profissionais resolvem dar opinião sobre a produção dos usuários ou dizer como as coisas devem ser feitas, mantendo uma relação de poder pautada no discurso técnico. Na oficina, isso é rompido no momento em que se legitima a produção diversa, e também é libertador para a equipe que é convidada a entrar em contato com sua própria produção e se deixar tocar pela produção dos usuários.

Auxiliares de enfermagem, a enfermeira e uma psiquiatra entraram no grupo e confeccionaram apliques de argila para o mosaico grupal. Mobilizados, continuaram a produção e fizeram dos apliques vários pingentes para colares que usaram e alguns que doaram como prenda para a festa junina. Um dos psiquiatras costumava entrar no grupo e opinar sobre a produção dos usuários, dizia o que gostava e o que não gostava, que cor achava que deveria ser usada ou o posicionamento de certos elementos nas composições. Num determinado dia, entrou no grupo e deu de encontro com o chão de terra pintado por um usuário que, durante uma sessão inteira de trabalho na mistura das cores, reproduziu a cor da terra da cidade em que nasceu. Ao se deparar com aquela figura de um lavrador num chão de terra vermelha, o psiquiatra exclamou que aquela era a cor da terra da sua infância e, então, o usuário e o psiquiatra passaram a trocar memórias e lembranças. Nesse momento, rompeu-se com a hierarquia mencionada e o contato humano-humano foi acionado por uma experiência estética compartilhada.

Numa operação bricoladora, usuários e técnicos se encontravam nos gestos e formas sensoriais criadas, num trabalho de articulação semântica de modos de ser e maneiras de fazer, que reconfigurava a geografia de práticas e criava outras representações em relação aos pacientes, suas capacidades criadoras e possibilidades de participação social. A composição artística e espacial instaurava uma mudança de lugar para todos. Estamos falando de um processo de ação e criação no mundo, no qual maneiras de fazer são formas ou campos de experimentação e operam a inscrição do humano no mundo. No processo de criação artística, o indivíduo cria formas imagéticas e sensoriais que veiculam sensações e visões de mundo. Quando estas sensações são atualizadas pela presença de um outro significativo permitem que a pessoa constitua aspectos do seu self, podendo então existir no mundo (Safra, 1999).

O contato com a materialidade das formas e a processualidade da criação artística intervém no espaço compartilhado com os outros, produz uma articulação semântica do inusitado, do estranho e do genuíno, transforma a rotina e os espaços já preestabelecidos e os ressignifica a partir da potência criativa.

Quem entra no CAPS de Guarulhos, depara-se com uma árvore povoada de figuras humanas; quem por seus corredores caminha, entra em contato com cenas de amor e outras de crítica, formas que lembram animais submarinos; quem lá se alimenta, convive com esqueletos e objetos cotidianos que adornam as cabeças no refeitório. "Onde pego a medicação? - É naquele balcão das plantas e das borboletas".

A oficina propunha que as experiências de criação dos sujeitos fossem topologicamente ancoradas à arquitetura da instituição e processualmente ancoradas ao seu fluxo contínuo cotidiano. 
Segundo Kujawski (1988), o cotidiano inclui o indivíduo no plano da vida em comunidade e a sucessão contínua de seus acontecimentos funciona como uma gramática comunitária irrecusável, que preenchemos com nossa criatividade pessoal.

O cotidiano se constitui como uma processualidade que dá contorno a nossas experiências e, quando permanece em constante transformação, abre portas para que o sujeito transforme este trajeto. Essa continuidade instaura a vivência de processo para estes sujeitos cuja vida parecia estagnada numa sucessão de mesmos acontecimentos. A partir das experiências de criação em grupo, o que se vive já não é mais um mesmo, mas um mesmo transformado, por aquilo que se cria, um devir constante.

Em avaliação do processo de conclusão de um painel de pintura na oficina, os usuários manifestaram o interesse de permanecer em constante processo de trabalho. Ao finalizar o projeto, disseram que, após a redação de nossa dissertação, montaríamos o que denominaram de uma nova equipe de criação para fazer um outro projeto juntamente com novas pessoas. Também expuseram a necessidade de que esse trabalho ocorresse em outro espaço que não o CAPS, pois se tratava de um trabalho de cultura, tal qual eles haviam intitulado: "artecultural". Portanto, deveria ser compartilhado com um maior número de pessoas. Mostravam-se preocupados com a divulgação da produção e, também, da produção teórica sobre este processo na dissertação de mestrado.

Um dos usuários comparou o processo de realização das atividades em grupo com sua experiência de trabalho em empresas. "Dá vontade de continuar. Um trabalho puxa o outro e isso não pára nunca." (sic.). Obviamente, para ele, esse fluxo parou na medida em que adoeceu e, por muitos anos, ele não se reconhecia fazendo parte de um processo compartilhado novamente.

A erosão habitual da gramática do cotidiano torna impraticável a realização do projeto individual de vida, por falta de apoio nessa infra-estrutura social que é a articulação organizada do cotidiano (Kujawski, 1988).

É uma articulação semântica e topológica das experiências dos sujeitos que ancoram estes no mundo humano. As atividades cotidianas promovem esta ancoragem e sustentação, pois apesar e mesmo porque tantas situações ocorrem conosco, o cotidiano permanece como pano de fundo que nos dá contorno e direção. Ele é o todo dia que se repete e nos dá a sensação de continuidade da nossa existência. O rio por onde nossas experiências navegam.

\section{Considerações finais}

Pensamos que o processo de realização de atividades artísticas pelos usuários do serviço deve ser articulado ao contexto mais amplo no qual eles se inserem: o cotidiano da instituição que permite aquela experiência, o cotidiano do sujeitos e a cultura. E para que a articulação deste fazer com a cultura aconteça e possa pôr em marcha um prosseguir do sujeito, a instituição e a qualidade da porosidade de seu cotidiano têm papel fundamental. A instituição e a forma como organiza seu cotidiano podem funcionar como ponte para esse processo de articulação, desde que suporte e dê lugar para o genuíno da produção dos sujeitos e de suas maneiras de fazer. E permaneça como pano de fundo necessário para que essas experiências se desenrolem provocando diálogos com o fora.

Mas ainda assim, é necessário que a instituição permaneça enquanto morada, para que os usuários possam habitá-la, tê-la de fato como referência para a construção de projetos quando necessário, possibilitando um ponto de partida para a ancoragem em outros territórios, permitindo a continuidade da existência e o sentimento de pertença.

Atualmente, a compreensão da experiência da Oficina de Bricolagem se estende para a maneira como esta auxilia os seus participantes na organização semântica de suas experiências cotidianas e facilita o reconhecimento, por eles próprios, de que sua produção possa ganhar trânsito no fora e sentido para outros. Pois, para que a experiência de fato promova sentimento de filiação para indivíduos que, em muitos momentos, não se sentem participantes do gênero humano ou de uma cultura, entende-se que o trabalho não se esgota na criação contínua de novos modos de ser, estes devem ganhar significação coletiva, para que, articulados a uma rede de sustentação, possam criar novos territórios de existência, afirmando as diferenças que surgem (Lima, 1997). 
Nesse trabalho, é possível perceber que esta significação coletiva já é engendrada na instituição pelo fato de que a oficina, em sua abertura para os processos de criação individuais e para as formas da cultura que com eles dialogam, engendra a semente da criação também na equipe. Em muitas sessões, era possível ver técnicos instigados pelo que se realiza na oficina, entrando e fazendo trabalhos próprios. Se aquilo que se faz na oficina é "artecultural", como dizem os participantes, é algo que provoca mudança em todos e, nesse momento, a hierarquia entre técnicos e pacientes, comum nos serviços de saúde, é rompida. É importante que todos criem, técnicos e usuários, dêem forma para o que é genuíno em si, construam espaço para a diversidade.

Segundo Guatarri (2005), é no conjunto de frentes emaranhadas e heterogêneas que deverão articular-se as novas práticas ecológicas, cujo objetivo é o de tornar processualmente ativas singularidades isoladas, girando em torno de si mesmas. Engajadas num processo de heterogênese, deve-se deixar se desenvolverem as culturas particulares, inventando-se, ao mesmo tempo, outros contatos de cidadania.

\section{Referências}

CASTRO, E.D. Arte, corpo e terapia ocupacional: aproximações, intersecções e desdobramentos. Rev. Ter. Ocup., v.11, n.1, p.7-12, 2000.

CERTEAU, M. A invenção do cotidiano: artes do fazer. Petrópolis: Vozes, 1998.

DELEUZE, G. Conversações. São Paulo: Ed. 34, 1992.

DIAS, M.O.S. Hermenêutica do quotidiano na historiografia contemporânea. Rev. Projet. História São Paulo, n.17, p.223-58, 1998.

GUATARRI, F. As três ecologias. São Paulo: Papirus, 2005.

HELLER, A. O cotidiano e a história. Rio de Janeiro: Paz e Terra, 1972.

KUJAWSKI, G.M. A crise do século XX. São Paulo: Ática, 1988.

LIMA, E.F. A terapia ocupacional: um território de fronteira? Rev. Ter. Ocup., v.8, n.2/3, p.98-101, 1997.

MAXIMINO, V.S. Rotinas e cotidianos. J. Inf. On-line, 2006. Disponível em: <http:// www.scamilo.edu.br>. Acesso em: 30 ago. 2006.

MEYER, J. Usando métodos qualitativos na pesquisa-ação relacionada à saúde. In: POPE, C.; MAYS, N. (Orgs.). Pesquisa qualitativa na atenção à saúde. 2.ed. Porto Alegre: Artmed, 2005. p.71-86.

SAFRA, G. A face estética do self: teoria e clínica. São Paulo: Unimarco, 1999.

SARACENO, B. Libertando identidades: da reabilitação psicossocial à cidadania possível. Belo Horizonte: Instituto Franco Basaglia/ TeCorá, 1999.

SENNETT, R. Carne e pedra: o corpo e a cidade na civilização ocidental. Rio de Janeiro: Record, 1997.

WINNICOTT, D.W. Tudo começa em casa. São Paulo: Martins Fontes, 1996. 
EXPERIÊNCIA ESTÉTICA E COTIDIANO INSTITUCIONAL...

MECCA, R.C.; CASTRO, E.D. Experiencia estética y cotidiano institucional: nuevos mapas para tornar subjetivos los espacios destinados a la salud mental. Interface - Comunic., Saúde, Educ., v.12, n.25, p.377-86, abr./jun. 2008.

Se discute el uso de las actividades artísticas como promotoras de prácticas de cuidados en salud mental, vinculadas a la organización del cotidiano y del espacio institucional en servicios substitutivos como los Centros de Atención Psico-social. Se discurre sobre la importancia de la porosidad de dicho cotidiano para la acogida de la creación de los usuarios, su articulación con las demás actividades que forman la estructura del cotidiano y habitar los espacios institucionales. Se defiende la necesidad de que el espacio institucional refleje el estilo de ser y las necesidades de las personas que allí se tratan y de que la institución funcione como telón de fondo para la articulación semántica de las experiencias de los sujetos y sus posibles diálogos con la cultura.

Palabras clave: Terapia ocupacional. Institucionalización. Salud mental. Cultura. Atividades cotidianas.

Recebido em 23/01/07. Aprovado em 28/11/07. 